\title{
EVALUATION OF THE RELATIVE PROTECTION FACTOR OF ROSEMARY EXTRACT IN BIODIESEL IN THE PRESENCE OF TRANSITION METAL IONS
}

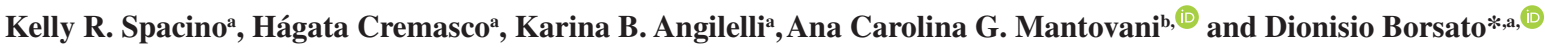 \\ aDepartamento de Química, Universidade Estadual de Londrina, PR-445 Km 380, 86057-970 Londrina - PR, Brasil

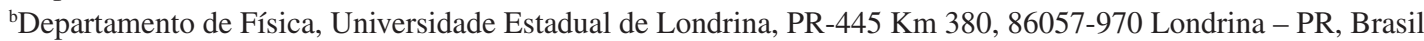

Recebido em 07/02/2020; aceito em 22/06/2020; publicado na web em 10/08/2020

\begin{abstract}
Biodiesel contains unsaturated methyl esters making it susceptible to oxidation reaction. Among the factors that cause oxidative instability is the contamination by transition metal ions that in small quantities catalyze the oxidation reaction. The objective of this work was to evaluate the relative protection factor of rosemary extract, in biodiesel, in the presence of transition metal ions. Chromatographic analysis and characterization of biodiesel were performed as well as the quantification of total phenolic compounds and extract activity. The ions $\mathrm{Cr}^{3+}, \mathrm{Co}^{2+}$ and $\mathrm{Fe}^{2+}$, at a concentration of $3.95 \times 10^{-3} \mathrm{~mol} \mathrm{~L}^{-1}$, were added to the biodiesel with and without rosemary extract. The samples were submitted to the Rancimat test and to infrared region analyses. The infrared region spectra of the samples with $\mathrm{Cr}^{3+}$ are in accordance with the least catalytic power of this ion under the biodiesel oxidation. Samples with $\mathrm{Co}^{2+}$ ions, without extract, presented bands of aldehydes, and samples with $\mathrm{Fe}^{2+}$ ions show the formation of peroxide radicals, without rosemary extract at $48 \mathrm{~h}$. The antioxidant effect of the extract in biodiesel is observed by the reduction of the induction period of the samples. The relative protection factor proved to be a good tool to evaluate its efficiency.
\end{abstract}

Keywords: catalyst, Chromium, Cobalt, Iron, oxidation reaction.

\section{INTRODUCTION}

Biodiesel been used as a partial substitute for diesel in automotive engines, although there are still some differences between them. Some advantages of biodiesel are: it is derived from renewable raw material, has a higher flash point $\left(130\right.$ to $\left.180{ }^{\circ} \mathrm{C}\right)$ compared to conventional diesel $\left(50^{\circ} \mathrm{C}\right)$ which makes its handling and storage safer. ${ }^{1}$

Because it contains methyl esters derived from unsaturated fatty acids, biodiesel is susceptible to oxidation which, although environmentally favorable, is one of its main technical disadvantages as the difficult for long-period storage. ${ }^{2}$ Among the factors that cause this instability are: humidity, light, high temperatures and metals contamination. . $^{2,3}$

The metal contamination can occur during biodiesel production, more precisely in heat exchangers, in storage tanks, during transportation and in its use in vehicles when in contact with the fuel tank, filter components, injector pump and others, since they are made of various transition metals. ${ }^{4,5}$

Some studies have shown the action of various metals in the oxidation reaction of biodiesel, ${ }^{6-8}$ and in the presence of transition metals, states that even in small quantities they significantly accelerate oxidation. Among metals, copper and iron in their ionic form have been the main reaction catalysts. ${ }^{6,-11}$

The oxidation reaction of biodiesel produces free radicals and hydroperoxides that form a series of by-products, such as aldehydes, ketones, carboxylic acids, among others. ${ }^{12-14}$ The mechanisms involved in oxidation are complex, and according to Kumar (2017) ${ }^{2}$ metals act as catalysts in the initiation step.

Antioxidants, including natural ones, have been widely used to reduce oxidative degradation of biodiesel as they act as free radical scavengers, metal ion chelators or even as oxygen scavengers. ${ }^{5,15}$ Phenolic compounds present in plant extracts have been used as antioxidants because they are capable of donating a hydrogen, by restoring the biodiesel molecule to more stable compounds, while

*e-mail: dborsato@uel.br the radicals formed by them are stabilized by resonance without the ability of initiate or propagate oxidative reaction. ${ }^{5,16}$

Chendynski et al., ${ }^{17}$ evaluated the action of extracts of rosemary leaves, araçá pulp and peel of bacuri in the inhibition of the biodiesel oxidation reaction. Messias et al., ${ }^{3}$ used rosemary extract in biodiesel catalyzed with metal alloys and obtained good performance of the extract as a natural antioxidant.

The effectiveness of an antioxidant is evaluated by increasing the induction period (IP) of biodiesel by the addition of extract with antioxidant properties, being expressed as a relative protection factor (RPF). Some studies have used the RPF to evaluate the efficiency of antioxidants in the biodiesel oxidation reaction. ${ }^{18-21}$ This study aimed to evaluate the antioxidant protection effect (RPF) of rosemary extract in biodiesel in the presence of transition metal ions.

\section{EXPERIMENTAL SECTION}

\section{Biodiesel}

The biodiesel used was obtained in the Fuel Research and Analysis Laboratory of the State University of Londrina, Brazil, from a mixture containing soybean oil, beef tallow and poultry fat, by methyl route.

\section{Chromatographic analysis}

The biodiesel esters profile and quantification were performed following EN 14103 (2003)22 using a gas chromatograph with CG-Shimadzu-GC2010-plus equipment coupled to a Shimadzu MS-QP2010-Ultra mass spectrometer.

\section{Rosemary leaves alcoholic extract}

Ten grams of dried rosemary leaves (Rosmarinus sp.) at $60{ }^{\circ} \mathrm{C}$ were added to $250 \mathrm{~mL}$ of absolute ethyl alcohol. These mixtures were kept in the absence of light for $48 \mathrm{~h}$, then filtered and concentrated 
to approximately $50 \mathrm{~mL}$ using a heating plate at $50^{\circ} \mathrm{C}$. After cooling to the room temperature, each extract was transferred to a $50 \mathrm{~mL}$ volumetric flask and completed with absolute ethyl alcohol (Anidrol). Before being added to biodiesel, rosemary extract was heated to $40^{\circ} \mathrm{C}$ until alcohol was eliminated.

\section{Determination of total phenolic and antioxidant activity of rosemary extract}

Total phenolic compounds of the extract were determined in triplicate by spectrophotometry (PerkinElmer, UV - vis LAMBDA 25 model) using Folin - Ciocalteu 2N reagent (Sigma - Aldrich) and the antioxidant activity was measured in triplicate by the DPPH assay (Sigma - Aldrich). ${ }^{23}$

\section{Chromatographic analysis of the extract}

The rosemary extract chromatographic analyses were performed on a Finnigan Surveyour Thermo Scientific liquid chromatograph, equipped with a photodiode array detector (HPLC-PAD), with wavelength monitoring at 190, 220 and $330 \mathrm{~nm}$.

\section{Samples Preparation}

Biodiesel samples were prepared individually by adding $\mathrm{Cr}^{3+}\left(\mathrm{CrCl}_{3} \cdot 6 \mathrm{H}_{2} \mathrm{O}\right.$; Cinética Brand, $97.0 \%$ purity $), \mathrm{Co}^{2+}\left(\mathrm{CoCl}_{2} \cdot 6 \mathrm{H}_{2} \mathrm{O}\right.$; Biotec Brand, $98.0 \%$ purity), $\mathrm{Fe}^{2+}\left(\mathrm{FeCl}_{2} .4 \mathrm{H}_{2} \mathrm{O}\right.$; Synth Brand, $99.6 \%$ purity) at a concentration of $3.9510^{-3} \mathrm{~mol} \mathrm{~L}^{-1}$ of cation with $2 \%_{(\mathrm{w} / \mathrm{w})}$ of rosemary extract. Besides iron, the main component of steel, chromium and cobalt salts were used since they are present in some alloys utilized in industry, storage tanks and transportation..$^{24,25}$ The concentration of cations used was determined by means of preliminary tests, so that, it was possible to monitor the reaction throughout the test period, enabling comparisons. Control samples were prepared using $200 \mathrm{~mL}$ of biodiesel (BC) and another $200 \mathrm{~mL}$ of biodiesel containing $2 \%_{(\mathrm{w} / \mathrm{w})}$ alcohol-free rosemary extract (BCE), concentration that allowed to obtain a biodiesel (control) with 8.29 hours of induction period, minimum value required by the standard EN $14112 .{ }^{26}$ With the exception of the control that was stored for 5 days, the remaining samples were stored for 4 days at room temperature and in the absence of light.

\section{Biodiesel physico-chemical characterization}

The density $\left(20^{\circ} \mathrm{C}\right)$ was determined according to the ASTM D4052 $2^{27}$ method, the kinematic viscosity $\left(40{ }^{\circ} \mathrm{C}\right)$ by the ASTM D445 method, ${ }^{28}$ acid number by the ASTM D664 method, ${ }^{29}$ iodine value by the EN $14111^{30}$ method, and water contend by the ASTM D6304 method. ${ }^{31}$

\section{Determination of Induction Period (IP)}

The assays were performed at $110{ }^{\circ} \mathrm{C}$, using the Rancimat equipment (Brand: Metrohm; Model: 873), according to the methodology described in EN 14112 (2016). ${ }^{26}$

\section{Infrared Analysis}

Infrared analyses were performed using a Shimadzu spectrophotometer, IRPrestige-21. The analyses used 64 scans with a resolution of 4.0. $\mathrm{KBr}$ pellets were made and 1 drop of each sample was placed on them.

\section{Relative Protection Factor (RPF)}

The relative protection factor (RPF) was determined from the ratio between the induction period of $\mathrm{B} 100$ biodiesel containing the antioxidant extract and the metal ion $\left(\mathrm{IP}_{\mathrm{ME}}\right)$, and the induction period of the biodiesel sample with the metal ion $\left(\mathrm{IP}_{\mathrm{M}}\right)$, according Equation (1).

$$
R P F=\frac{I P_{M E}}{I P_{M}}
$$

\section{RESULTS AND DISCUSSION}

The biodiesel used in the experiment showed $879.6 \mathrm{~kg} \mathrm{~m}^{-3}$ of density, $4.46 \mathrm{~mm}^{2} \mathrm{~s}^{-1}$ of kinematic viscosity $\left(40^{\circ} \mathrm{C}\right), 0.45 \mathrm{mg}_{\text {Кон }} \mathrm{g}^{-1}$ of acid number, $92 \%$ mass of iodine value and $180 \mathrm{mg} \mathrm{kg}^{-1}$ of water content. The chromatographic analyses indicated the presence of $98.71 \% \%_{(\mathrm{w} / \mathrm{w})}$ of esters, being $42.02 \%$ saturated methyl esters and $57.98 \%$ unsaturated methyl esters, in which, although not containing antioxidants in its composition, justifies its induction period of $8.29 \mathrm{~h}$. However, since biodiesel has unsaturated methyl esters in its composition, it is subject to the oxidation process that can be accelerated in the presence of some transition metal cations. ${ }^{32}$

To inhibit or delay the oxidation reaction of biodiesel, rosemary extract was added, which has in its composition chemicals substances with antioxidant properties, such as: rosmarinic acid, rosmanol, carnosic acid, carnosol and methyl carnosol. ${ }^{33,34}$ These phenolic compounds are capable of donating hydrogens that interrupt the propagation of free radicals formed at the beginning of oxidation, and according to Moreno et al., ${ }^{34}$ act as metal chelating agents or as singlet oxygen deactivators.

To verify the efficiency of the rosemary extract, before its addition in the biodiesel samples, the phenolic compounds content was analyzed and the value found was $19.285 \mathrm{mgGAE} \mathrm{g}_{\text {drymass }}^{-1}$. According to Spacino et al. ${ }^{35}$ the concentration of phenols in rosemary extract varies from 11.60 to $34.23 \mathrm{mgGAE} \mathrm{g}^{-1}$ drymass, but it depends on how the extract was obtained, the temperature, climate and region where rosemary was grown. The antioxidant activity, which gives an idea of the quality of the phenolic compounds present in the extract, expressed as Trolox equivalent, was $54.209 \mathrm{mgTrolox} \mathrm{g}^{-1}$ drymass , similar to that found by Spacino et al.. ${ }^{35}$

The Chromatographic analysis of the extract shows the presence of rosmarinic acid, rosmanol, carnosic acid, carnosol and methyl carnosate, which are phenolic compounds present in rosemary that have antioxidant properties. Furthermore, according to Coppo et al. (2013), ${ }^{36}$ the infrared spectra of alcoholic rosemary extract showed characteristic bands of phenolic compounds.

Biodiesel samples containing metallic ions, in the presence and absence of rosemary extract, were subjected to the accelerated oxidation test, using the Rancimat equipment, to determine the induction period (IP). The temperature of $110^{\circ} \mathrm{C}$ was used following the methodology described by the standard EN 14112 (2016). ${ }^{26}$ According to Spacino et al., ${ }^{23}$ rosemary extract does not undergo thermal decomposition at this temperature because thermogravimetric analysis showed that the first decomposition event occurs only from a temperature of $121.6^{\circ} \mathrm{C}$.

Table 1 shows the IP of biodiesel samples, without and with rosemary extract, represented by $\mathrm{BC}$ and $\mathrm{BCE}$, respectively; samples containing the transition metal ions without extract, represented by $\mathrm{BCr}, \mathrm{BCo}$ and $\mathrm{BFe}$, respectively, and with the extract addition represented by $\mathrm{BCrE}, \mathrm{BCoE}$ and $\mathrm{BFeE}$. The dashed lines separate the biodiesel containing or not rosemary extract at the beginning and in the end of the experiments. For the 72 hours of the BFe sample and 
Table 1. Induction period at $110{ }^{\circ} \mathrm{C}$ of control samples and samples with metallic ions with and without extract addition

\begin{tabular}{|c|c|c|c|c|c|c|}
\hline \multicolumn{7}{|c|}{ Induction Period (h) } \\
\hline Time (h) & & $\mathrm{BC}$ & & & BCE & \\
\hline \multirow[t]{2}{*}{0} & & 8.29 & & & 11.42 & \\
\hline & $\mathrm{BCr}$ & $\mathrm{BCo}$ & $\mathrm{BFe}$ & $\mathrm{BCrE}$ & $\mathrm{BCoE}$ & $\mathrm{BFeE}$ \\
\hline 0.25 & 7.23 & 6.59 & 5.13 & 9.97 & 11.19 & 11.40 \\
\hline 8 & 6.40 & 6.59 & 4.51 & 9.82 & 10.82 & 11.21 \\
\hline 24 & 4.36 & 5.84 & 3.37 & 9.79 & 10.30 & 7.62 \\
\hline 32 & 4.05 & 4.85 & 2.23 & 9.33 & 9.67 & 6.14 \\
\hline 48 & 2.43 & 3.85 & 2.06 & 8.61 & 8.90 & 3.66 \\
\hline 56 & 1.76 & 3.76 & 1.28 & 8.58 & 8.52 & 2.91 \\
\hline 72 & 1.20 & 1.89 & NR & 8.55 & 7.36 & 1.54 \\
\hline \multirow[t]{2}{*}{96} & NR & NR & NR & 8.05 & 5.59 & 1.18 \\
\hline & & $\mathrm{BC}$ & & & BCE & \\
\hline 120 & & 7.36 & & & 10.03 & \\
\hline
\end{tabular}

NR not registered

the 96 hours of the $\mathrm{BCr}, \mathrm{BCo}$ and $\mathrm{BFe}$ samples, the Rancimat did not register the induction periods.

The initial time samples, which correspond to the control without extract $(\mathrm{BC})$ and with addition of extract $(\mathrm{BCE})$, presented IP of $8.29 \mathrm{~h}$ and $11.42 \mathrm{~h}$, respectively. These values were higher than the established by EN 14214 (2019) ${ }^{37}$ which minimum value is $8 \mathrm{~h}$. After $120 \mathrm{~h}$ of experiment, the BC sample had an $11.21 \%$ reduction in its IP and the BE sample a reduction of $12.17 \%$. Although the BC sample presented IP of $7.36 \mathrm{~h}$ after $120 \mathrm{~h}$ of experiment, this value was 3.89 times higher than the value presented by BCo sample after $72 \mathrm{~h}$ of experiment.

For the biodiesel samples containing the metal ions without extract, after the beginning of the experiment, none of the samples presented IP higher than $8 \mathrm{~h}$. However, we verified that the cobalt ion-containing biodiesel showed the highest IP throughout the experiment, when compared to the samples containing the other metals. The sample containing iron ions, after $56 \mathrm{~h}$, had a reduction of $84.56 \%$ of the initial IP, indicating that iron was the one that most accelerated the oxidation reaction.

Analyzing the biodiesel samples containing the metal cations and the rosemary extract, we found that the extract exerted greater protection in the BCrE sample, because until the 96-hour experiment time, it was still in conformity with EN 14214 (2019). ${ }^{37}$ The extract was also a good antioxidant in the $\mathrm{BCoE}$ sample that remained within the norm until $56 \mathrm{~h}$ of experiment. The BFeE sample presented the lowest IP, consequently the one that oxidized more rapidly and with the lowest antioxidant effect, since after $24 \mathrm{~h}$ of experiment it was no longer in compliance with EN 14214 (2019). ${ }^{37}$

Through the IP values of the samples with and without the addition of rosemary extract, the values of the extract RPF (Equation 1) were determined against the catalytic action of the metal ions used (Table 2).

In Table 2 we can see that the biodiesel sample containing chromium ions, the RPF increased 5.16 times after $72 \mathrm{~h}$ of experiment, and those with cobalt ions the increase was smaller, 2.82 times. In the iron-containing sample there was practically no variation in the RPF.

Despite the catalytic action of transition metal ions in the oxidation reaction of biodiesel, we found a strong protective effect of the phenolic compounds present in rosemary extract in the chromium ion-containing sample, which is confirmed when we also compare the IP value (Table 1), because the $\mathrm{BCrE}$ sample has an IP greater
Table 2. Rosemary extract RPF values for biodiesel samples containing metallic cations

\begin{tabular}{cccl}
\hline \multicolumn{4}{c}{ Relative Protection Factor } \\
\hline Time $(\mathrm{h})$ & $\mathrm{Cr}^{3+}$ & $\mathrm{Co}^{2+}$ & $\mathrm{Fe}^{2+}$ \\
\hline 0 & 1.38 & 1.38 & 1.38 \\
0.25 & 1.38 & 1.7 & 2.22 \\
8 & 1.53 & 1.64 & 2.48 \\
24 & 2.24 & 2.36 & 2.26 \\
32 & 2.30 & 2.00 & 2.75 \\
48 & 3.54 & 2.31 & 1.77 \\
56 & 4.87 & 2.26 & 2.27 \\
72 & 7.12 & 3.89 & $\mathrm{NR}$ \\
\hline
\end{tabular}

NR not registered

than $\mathrm{BCr}$ throughout the experiment time. Although iron has higher catalytic power in the oxidation reaction of biodiesel, the relative protection factor of the extract showed low values in the sample containing this ion.

In the initial times, the RPF of the sample containing $\mathrm{Cr}^{3+}$ showed no significant variation, indicating that the initiation of the oxidation reaction with free radical formation is slower in the presence of this metal when compared to samples containing $\mathrm{Co}^{2+}$ and $\mathrm{Fe}^{2+}$ ions. In the final times the RPF value of this sample increased considerably, since a mechanism of free radical formation has already been established. However, in samples containing the extract we have the inhibition of intermediate radicals, which does not occur in samples free of extract.

When analyzing the possibility of complexation of phenolic radicals with metal ions, which would decrease their availability, and thereby decrease their ability to catalyze oxidation reactions. Thus, the different complexation trends of these metals should be taken into account as well as their stability. Phenolic compounds are classified as strong field ligands, ${ }^{38}$ and if we consider an ideal situation where the possible complexes are undistorted octahedra and non-interference by other compounds, it is simple to justify the behavior.

Among the factors that affect the tendency to complex formation and their stability is the crystal field stabilization energy (CFSE), which depends on the magnitude of the crystal field splitting values 
$\left(\Delta_{o}\right)$ and the electronic configuration of the metal ion. The $\Delta_{o}$ is greater the higher the load on the metal and the smaller its radius. Therefore $\mathrm{Cr}^{3+}$ is the metal with the highest load and the smallest radius among those used, having the highest value of $\Delta_{o}$.

$\mathrm{Co}^{2+}$ and $\mathrm{Fe}^{2+}$ have the same charge, but cobalt is slightly smaller than iron and thus has a higher value of $\Delta_{o}$. Considering also the dependence of CFSE with the electronic configuration, $\mathrm{Cr}^{3+}$ presents configuration $\mathrm{d}^{3}$, while $\mathrm{Co}^{2+}$ and $\mathrm{Fe}^{2+}$ are $\mathrm{d}^{7}$ and $\mathrm{d}^{6}$, respectively. Therefore, they have an increasing CFSE ratio of $\mathrm{Fe}^{2+}<\mathrm{Co}^{2+}<\mathrm{Cr}^{3+}$. These data show the greater tendency of the $\mathrm{Cr}^{3+}$ ion to form complexes followed by $\mathrm{Co}^{2+}$ and $\mathrm{Fe}^{2+}$ respectively, thus agreeing with the experimental results since $\mathrm{Fe}^{2+}$, being freer, is the metal with the greatest catalytic action in the presence of extract and $\mathrm{Cr}^{3+}$ of less action.

This greater availability of $\mathrm{Fe}^{2+}$ in the nonpolar medium causes the formation of complexes with the ions and the compounds produced during the initiation step of the biodiesel oxidation reaction. In these complexes, the electrons transfer to oxygen forming the singlet oxygen, reacting with the unsaturated ester, forming the free peroxide radical, and then the hydroperoxide forming the alkoxy and hydroxy radical, rapidly propagating the oxidation reaction of the biodiesel esters. ${ }^{39-41}$ Moreover, as the reaction of this ion with oxygen forms $\mathrm{Fe}^{3+}$ and singlet oxygen that reacts with unsaturated ester, propagating the oxidation reaction of biodiesel. ${ }^{39,40}$

Figures 1 to 3 represent the infrared spectra of biodiesel samples with and without rosemary extract containing $\mathrm{Cr}^{3+}$ ions (Figure 1a and 1b), biodiesel with and without rosemary extract containing $\mathrm{Co}^{2+}$ ions (Figure $2 \mathrm{a}$ and $2 \mathrm{~b}$ ) and biodiesel with and without rosemary extract containing $\mathrm{Fe}^{2+}$ ions (Figure $3 \mathrm{a}$ and $3 \mathrm{~b}$ ).

Infrared spectra for samples containing $\mathrm{Cr}^{3+}$ (Figure 1) showed no difference in absorption bands in relation to the absence or presence of the extract. $\mathrm{Cr}^{3+}$ did not show pronounced catalytic power in biodiesel oxidation, and the processes with free radical formation occurred practically independently of the presence of the metal ion.

The RPF of samples containing $\mathrm{Co}^{2+}$ presented a more discreet variation when compared to samples containing $\mathrm{Cr}^{3+}$, and at the end of $72 \mathrm{~h}$, had a protection 2.8 times higher than at the beginning of the experiment. From the spectra of the samples containing $\mathrm{Co}^{2+}$ (Figure 2b) in the absence of rosemary extract after $96 \mathrm{~h}$, a $2750 \mathrm{~cm}^{-1}$ band of axial deformation of the C-H bond of aldehydes is observed. This band shows that the mechanism of the $\mathrm{Co}^{2+}$ ion led to the formation of perhydroxyl radicals, precursor of aldehydes
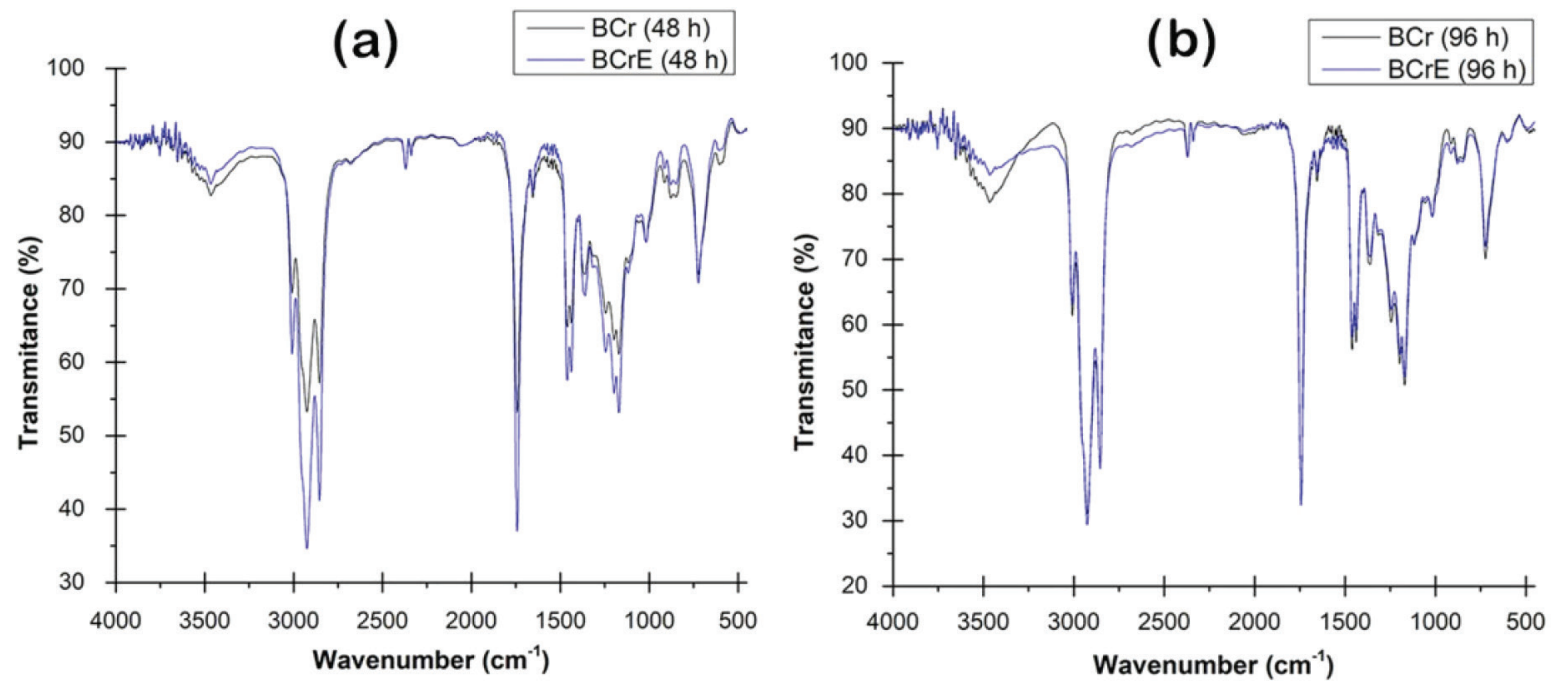

Figure 1. Infrared spectrum of biodiesel samples containing chromium ions with and without rosemary extract (BCr and BCrE) at 48 (a) and 96 h (b), intermediate and final times of the experiment, respectively
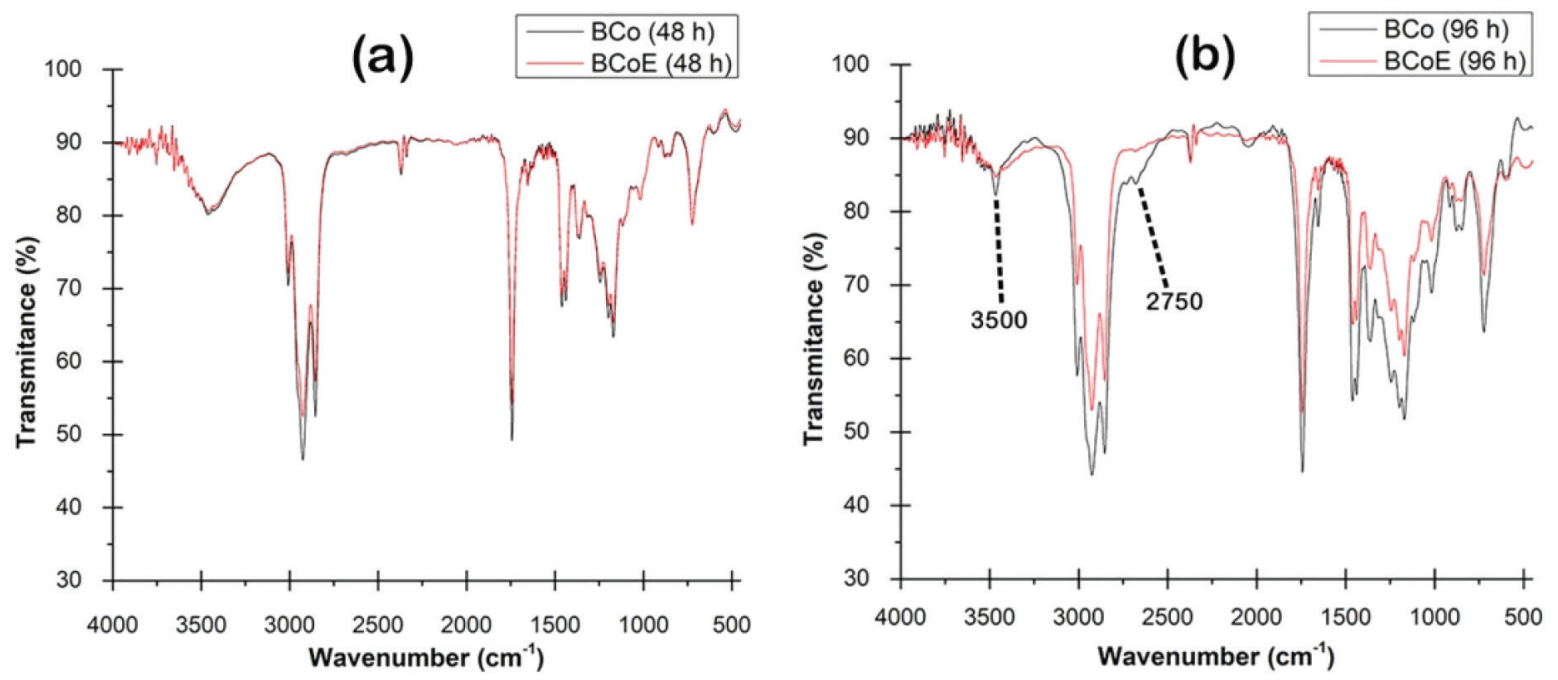

Figure 2. Infrared spectrum of biodiesel samples containing cobalt ions without and with rosemary extract (BCo and BCoE) at 48 (a) and 96 h (b), intermediate and final times of the experiment, respectively 

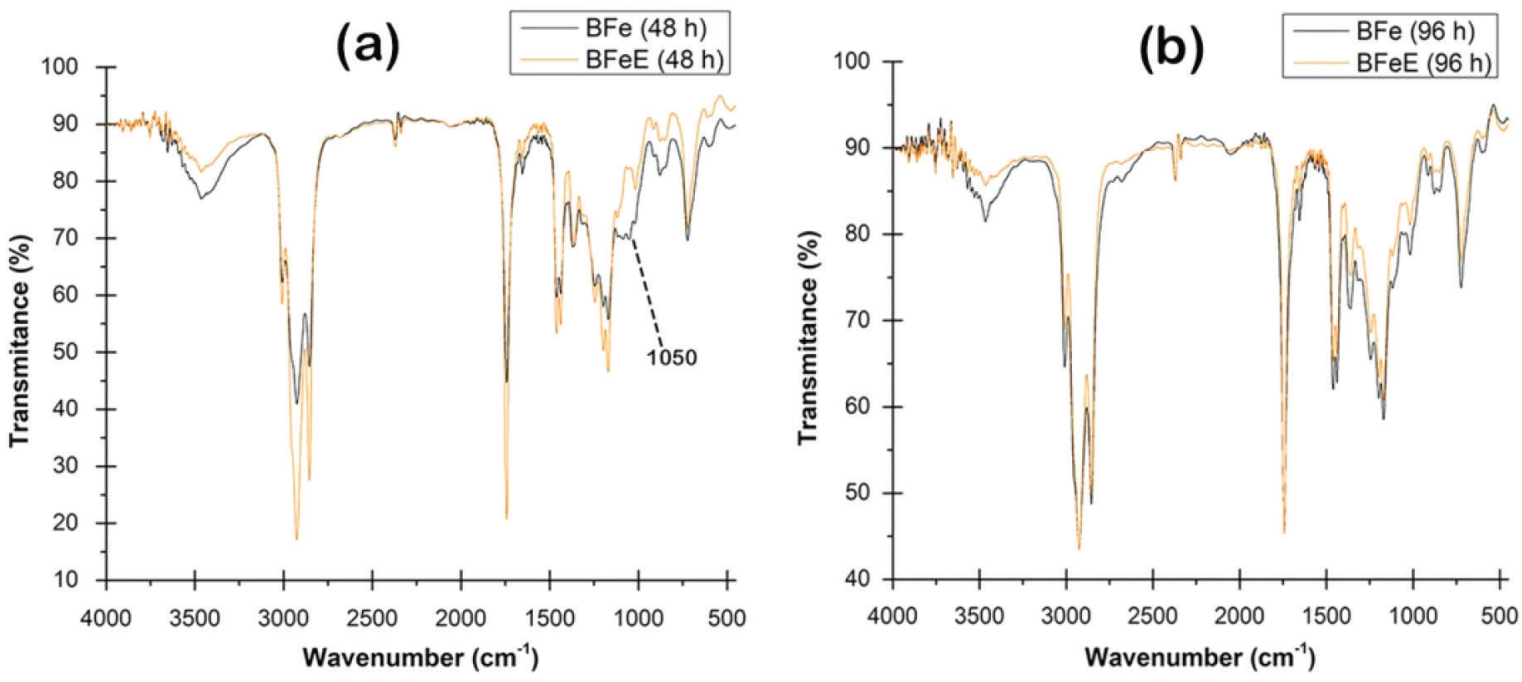

Figure 3. Infrared spectrum of biodiesel samples containing iron ions without and with rosemary extract (BFe and BFeE) at 48 (a) and 96 h (b), intermediate and final times of the experiment, respectively

and ketones in the oxidation of lipids and long chain esters..$^{42}$ This mechanism is also confirmed by the presence of a narrower band at $3500 \mathrm{~cm}^{-1}$, indicating the presence of $\mathrm{O}-\mathrm{H}$ bond in free species such as the hydroxyl radical. The bands discussed are not observed in the spectrum of the sample containing rosemary extract, evidencing their efficiency in inhibiting the reactions of free radical formation.

For samples containing $\mathrm{Fe}^{2+}$, the opposite behavior is observed (Table 2), since the largest increase in RPF is observed in the first 0.25 $\mathrm{h}$ of the experiment. In this case, the metal leads to a faster initiation of free radical formation and the effect of the antioxidant in the samples containing extract is observed by the decrease of the induction period. Over time, the RPF does not change widely, indicating that there are no changes in the reaction mechanism in subsequent times. Infrared spectra of the sample BFe at $48 \mathrm{~h}$ (Figure 3a) shows a large band at about $1050 \mathrm{~cm}^{-1}$, characteristic of peroxide radical species as acyl, alkyl and aryl. The presence of intermediate peroxides is in accordance with the literature that reports the mechanisms of $\mathrm{Fe}^{2+}$ catalysis,${ }^{40}$ and also explains the high reaction rate of biodiesel oxidation reactions in the presence of this metal ion. In the presence of rosemary extract the peroxide band observed is similar to other samples, possibly due to an interaction between the extract and the metallic ion, making its catalytic action in the oxidation of biodiesel less intense, which can be confirmed by the values of relative protection factor of the sample with the antioxidant extract.

\section{CONCLUSION}

The $\mathrm{Cr}^{3+}, \mathrm{Co}^{2+}$ and $\mathrm{Fe}^{2+}$ ions showed a catalytic effect in biodiesel oxidation reaction. Analyzing the induction period, the largest effect was caused by the iron ion.

The rosemary extract, besides restoring free radicals formed in the oxidation reaction of biodiesel, showed an interaction with the metal ions added, slowing the oxidative process. The antioxidant effect of the extract in the biodiesel samples is observed by the reduction of the induction period. The relative protection factor proved to be a good tool to evaluate the rosemary extract efficiency during the biodiesel storage.

\section{ACKNOWLEDGMENTS}

The State University of Londrina (UEL), Fuel Analysis and Research Laboratory (LPAC) and Spectroscopy Laboratory (LABSPEC) for the technical support.

\section{REFERENCES}

1. Saluja, R. K.; Kumar, V.; Sham, R.; Renew.Sust.Energy Rev. 2016, 62, 866.

2. Kumar, N.; Fuel 2017, 190, 328.

3. Messias, G. B.; Chendynski, L. T.; Gomes Mantovani, A. C.; Suquila, F. A. C.; Tarley, C. R. T.; Moreira, I.; Borsato, D.; Biofuels 2019, 1.

4. Mohammed, H. A.; Bhaskaran, G.; Shuaib, N. H.; Saidur, R.; Renew. Sust.Energy Rev. 2011, 15, 1502

5. Rizwanul Fattah, I. M.; Masjuki, H. H.; Kalam, M. A.; Hazrat, M. A.; Masum, B. M.; Imtenan, S.; Ashraful, A. M.; Renew.Sust. Energy Rev. 2014, 30, 356.

6. Fazal, M. A.; Suhaila, N. R.; Haseeb, A.; Rubaiee, S.; Al-Zahrani, A.; J. Clean. Prod. 2018, 171, 1407.

7. Hu, E.; Xu, Y.; Hu, X.; Pan, L.; Jiang, S.; Renew.Energy 2012, 37, 371.

8. Kovács, A.; Tóth, J.; Isaák, G.; Keresztényi, I.; Fuel Process. Technol. 2015, 134, 59.

9. Knothe, G.; Steidley, K. R.; Fuel Process.Technol. 2018, 177, 75.

10. Rocabruno-Valdés, C. I.; González-Rodriguez, J. G.; Díaz-Blanco, Y.; Juantorena, A. U.; Muñoz-Ledo, J. A.; El-Hamzaoui, Y.; Hernández, J. A.; Renew. Energy 2019, 140, 592.

11. Sui, M.; Li, F.; Renewable Energy 2019, 143, 352.

12. Bussler, L.; Izida, T.; Lima, S. M.; Andrade, L. H. C.; Spectrochim. Acta Part A: Molecular and Biomolecular Spectroscopy 2019, 217, 190.

13. Fazal, M. A.; Suhaila, N. R.; Haseeb, A.; Rubaiee, S.; J. Clean. Prod. 2018, 181, 508 .

14. Liu, Z.-W.; Li, F.-S.; Wang, W.; Wang, B.; J.Energy Inst. '2019, 92, 861.

15. Chendynski, L. T.; Romagnoli, É. S.; Mantovani, A. C. G.; Kimura, M.; Marquesa, L. C.; Borsato, D.; J.Brazil. Chem. Soc. 2019, 30, 90.

16. Chendynski, L. T.; Mantovani, A. C. G.; Savada, F. Y.; Messias, G. B.; Santana, V. T.; Salviato, A.; Di Mauro, E.; Borsato, D.; Fuel 2019, 242, 316.

17. Chendynski, L. T.; Cordeiro, T.; Messias, G. B.; Mantovani, A. C. G.; Spacino, K. R.; Zeraik, M. L.; Borsato, D.; Fuel 2020, 261, 116379

18. Gregório, A. P. H.; Borsato, D.; Moreira, I.; Silva, E. T.; Romagnoli, É. S.; Spacino, K. R.; Biofuels 2019, 10, 607.

19. Kimura, M.; Savada, F. Y.; Romagnoli, E. S.; Chendynski, L. T.; Borsato, D.; Rev.Virtual de Quimica 2019, 11, 1097.

20. Souza, A. G.; Medeiros, M. L.; Cordeiro, A. M. M. T.; Queiroz, N.; Soledade, L. E. B.; Souza, A. L.; Energ. Fuels 2014, 28, 1074.

21. Suja, K. P.; Abraham, J. T.; Thamizh, S. N.; Jayalekshmy, A.; Arumughan, C.; F. Chem. 2004, 84, 393. 
22. European Committee for Standardization. EN 14103: Fat and Oil Derivatives. Fatty Acid Methyl Esters (FAME). Determination of Ester and Linolenic Acid Methyl Ester Contents 2003.

23. Spacino, K. R.; da Silva, E. T.; Angilelli, K. G.; Moreira, I.; Galão, O. F.; Borsato, D.; Ind. Crop.Prod. 2016, 80, 109.

24. Bramfitt, B. L.; Benscoter, A. O. Metallographer's guide: practice and procedures for irons and steels; Asm International, 2001.

25. Callister Jr., W. D.; Materiais: Uma Introdução, $1^{a}$ ed., Rio de Janeiro, LTC 2002.

26. European Committee for Standardization. EN 14112: Determination of oxidation stability (accelerated oxidation test) 2016.

27. ASTM International ASTM D4052: Standard Test Method for Density, Relative Density, and API Gravity of Liquids by Digital Density Meter; ASTM International 2002.

28. ASTM D445: Standard Test Method for Kinematic Viscosity of Transparent and Opaque Liquids (and Calculation of Dynamic Viscosity); ASTM International 2007.

29. ASTM D664: Standard Test Method for Acid Number of Petroleum Products by Potentiometric Titration; ASTM International: 2011.

30. EN 14111: Fat and oil derivatives. Fatty acid methyl esters (FAME). Determination of iodine value 2003.

31. ASTM D6304: Standard Test Method for Determination of Water in Petroleum Products, Lubricating Oils, and Additives by Coulometric Karl Fischer Titration (Withdrawn 2016); ASTM International: 2004.
32. Orives, J. R.; Galvan, D.; Coppo, R. L.; Rodrigues, C. H. F.; Angilelli, K. G.; Borsato, D.; Energ. Convers.Manage. 2014, 79, 398.

33. Lee, K. H.; Lee, J.-S.; Kim, E. S.; Lee, H. G.; LWT 2019, 101, 138.

34. Moreno, S.; Scheyer, T.; Romano, C. S.; Vojnov, A. A.; Free Radic.Res. 2006, 40, 223.

35. Spacino, K. R.; Borsato, D.; Buosi, G. M.; Chendynski, L. T.; Fuel Process.Technol. 2015, 137, 366.

36. Coppo, R. L.; Borsato, D.; Pereira, J. L.; da Silva, H. C.; J. Renew. Energy 2013, 1.

37. European Committee for Standardization. EN 14214: Automotive fuels. Fatty acid methyl esters (FAME) for diesel engines-Requirements and test methods. 2019.

38. Huheey, J. E.; Keiter, E. A.; Keiter, R. L. Inorganic Chemistry: Principles of Structure and Reactivity; $4^{\text {th }}$ ed.; Harper Collins College Publishers: New York, 1993.

39. Aurand, L. W.; Boone, N. H.; Giddings, G. G.; J.Dairy Sci. 1977, 60, 363.

40. Schaich, K. M.; Bailey's industrial oil and fat products 2005.

41. Housecroft, C. E.; Sharpe, A. G.; Harlow UK: Pearson Education Ltd 2012.

42. Lillard, D. A.; Day, E. A.; J. Am. Oil Chem. Soc. 1964, 41, 549. 